\title{
Mechanical properties of biaxially strained poly(L-lactide) tubes: Strain rate and temperature dependence
}

\author{
Løvdal, Alexandra Liv Vest; Andreasen, Jens Wenzel; Mikkelsen, Lars Pilgaard; Agersted, Karsten; \\ Almdal, Kristoffer
}

\section{Published in:}

Journal of Applied Polymer Science

Link to article, DOI:

10.1002/app.45192

Publication date:

2017

Document Version

Peer reviewed version

Link back to DTU Orbit

Citation (APA):

Løvdal, A. L. V., Andreasen, J. W., Mikkelsen, L. P., Agersted, K., \& Almdal, K. (2017). Mechanical properties of biaxially strained poly(L-lactide) tubes: Strain rate and temperature dependence. Journal of Applied Polymer Science, 134(33), [45192]. https://doi.org/10.1002/app.45192

\section{General rights}

Copyright and moral rights for the publications made accessible in the public portal are retained by the authors and/or other copyright owners and it is a condition of accessing publications that users recognise and abide by the legal requirements associated with these rights.

- Users may download and print one copy of any publication from the public portal for the purpose of private study or research.

- You may not further distribute the material or use it for any profit-making activity or commercial gain

- You may freely distribute the URL identifying the publication in the public portal 


\section{Mechanical Properties of Biaxially Strained Poly(L-Lactide) Tubes: Strain Rate and Temperature Dependence}

Authors: Alexandra Liv Vest Løvdal ${ }^{1}$, Jens W Andreasen ${ }^{2}$, Lars P Mikkelsen ${ }^{3}$, Karsten Agersted ${ }^{2}$, Kristoffer Almdal ${ }^{1}$

Correspondence to: A. Løvdal, Technical University of Denmark, Department of Microtechnology and Nanotechnology, Ørsteds Plads, 345E, 2800 Kongens Lyngby, Denmark. E-mail: alvlo@nanotech.dtu.dk

${ }^{1}$ Technical University of Denmark, Department of Micro- and Nanotechnology. Ørsteds Plads, 345E, 2800 Kongens Lyngby, Denmark.

${ }^{2}$ Technical University of Denmark, Department of Energy Conversion and Storage.

Frederiksborgvej 399, 4000 Roskilde

${ }^{3}$ Technical University of Denmark, Department of Wind Energy. Frederiksborgvej 399, 4000 Roskilde

Correspondence to: A. Løvdal, Technical University of Denmark, Department of Microtechnology and Nanotechnology, Ørsteds Plads, 345E, 2800 Kongens Lyngby, Denmark. E-mail: alvlo@nanotech.dtu.dk

Corresponding Address: Technical University of Denmark, Department of Micro- and Nanotechnology, Ørsteds Plads, 345E, 2800 Kongens Lyngby, Denmark.

Corresponding author: A. Løvdal, alvlo@nanotech.dtu.dk/a.loevdal@gmail.com 


\begin{abstract}
Poly(L-lactide) is a bioabsorbable polymer with high stiffness and strength compared to the other commercially available bioabsorbable polymers. The properties of poly(L-lactide) can be improved by straining, causing deformation-mediated molecular orientation. Poly(L-lactide) tubes were biaxially strained above their $\mathrm{T}_{\mathrm{g}}$ for improvement of their strength, in a two-step process (sequential straining). Mechanical properties and crystal morphology were investigated as a function of processing strain rate and temperature. DSC revealed that a low processing strain rate allows molecular chain relaxation in the direction of strain and the crystallization is suppressed. Faster strain rates on the other hand suppress chain relaxation, and results in crystalline tubes. The mechanical properties are influenced by both processing strain rate and temperature. Low strain rates allow chain relaxation resulting in the lowest strength and stiffness, whereas a larger stiffness and strength is achieved by increasing in strain rate and temperature. Isotropic mechanical properties are only observed at high processing strain rates.
\end{abstract}




\section{INTRODUCTION}

Poly(L-lactide) (PLLA) belongs to a group of semi-crystalline polymers that exhibits slow crystallization. PLLA is well known for being biocompatible and bioabsorbable for use in medical devices $^{1-3}$ as well as being an environmentally friendly alternative to commodity polymers, currently used in the packaging industry ${ }^{4-6}$. Most of the semi-crystalline polymers, such as polypropylene and polyethylene terephthalate, can become oriented under deformation above the glass transition temperature $\left(\mathrm{T}_{\mathrm{g}}\right)$ altering and improving the mechanical properties for a particular application $^{7,8}$. PLLA has promising potential as a substitute for some petroleum based polymers. To widen the range of applications of PLLA improvement of the mechanical properties has been of high interest. The mechanical properties of PLLA can be improved through either axial or biaxial straining, which can induce oriented crystallization, chain orientation, fibrillary formation and cavitations ${ }^{8,10}$. The behavior of strained semi-crystalline polymers strongly depends on the strain temperature and strain rate ${ }^{11}$. Previous studies have examined the influence of the extent of straining, the strain rate and strain temperature, but have only measured the stress-strain behavior during the strain ${ }^{7,9,11-15}$. The mechanical behavior of a strained material as a function of processing strain rate $\left(\dot{\epsilon}_{\mathrm{p}}\right)$ or processing strain temperature $\left(\mathrm{T}_{\mathrm{p}}\right)$ has not been reported. It is shown that an increase in strain rate induces a higher stiffness and yield stress, and crystallinity and induces orientation ${ }^{16}$ during straining. Furthermore, an increase in crystallinity and orientation as a function of the extent of strain was also reported.

Our previous work has shown that it is possible to induce approximately $30 \%$ crystallinity upon biaxial straining of tubes, and further orient the amorphous domain and the secondary binding between strain-induced crystals. The process improved the mechanical properties as a function of extent of straining ${ }^{17}$. The induced crystallinity adds to the strength of the materials, whereas the amorphous domain adds to the flexibility ${ }^{18}$. High crystallinity causes the material to become brittle, and to avoid this, the straining temperature must be kept between $\mathrm{T}_{\mathrm{g}}$ and the cold crystallization temperature $\left(\mathrm{T}_{\mathrm{cc}}\right)$. By processing at temperatures closer to $\mathrm{T}_{\mathrm{g}}$ than $\mathrm{T}_{\mathrm{cc}}$ the equilibrium crystallization of PLLA is severely suppressed, and the strain-induced crystallinity will dominate.

The objective of the present study was to determine the final mechanical and thermal behavior of sequential, biaxially strained PLLA tubes as a function of $\dot{\epsilon}_{\mathrm{p}}$ and $\mathrm{T}_{\mathrm{p}}$. The study shows how the 
mechanical properties of PLLA can be further improved and how the crystallization can be suppressed.

\section{EXPERIMENTAL}

\section{Materials}

PLLA 2003D pellets from NatureWorks LLC (Minnetonka, MN, USA) ( 4.1 \% D-isomer; molecular weight, $1.85 \times 10^{5} \mathrm{~g} / \mathrm{mol}$ ) were extruded at $194{ }^{\circ} \mathrm{C}$ into small tubes after which they were quenched well below $\mathrm{T}_{\mathrm{g}}$ in a cooling medium at $15.5^{\circ} \mathrm{C}$ for $14.5 \mathrm{~s}$, leaving the tube with low crystallinity $(\sim 1 \%)$. The extruded tubes have an outer diameter of $3.4 \mathrm{~mm}$ and an inner diameter of $1.7 \mathrm{~mm}$. The extruded tubes were heated to the processing temperature, $\mathrm{T}_{\mathrm{p}}\left(73{ }^{\circ} \mathrm{C}, 85^{\circ} \mathrm{C}\right.$ or 93 ${ }^{\circ} \mathrm{C}$ ) followed by axially or biaxially straining. The chosen temperatures correspond to a temperature close to $\mathrm{T}_{\mathrm{g}}$, one intermediate temperature, and one close to $\mathrm{T}_{\mathrm{cc}}$. The tubes were axially strained by $100 \%$ at processing strain rates $\left(\dot{\epsilon}_{\mathrm{p}}\right)$ of $0.1,0.2$ or $2.1 \mathrm{~s}^{-1}$ followed by cooling. Some of these tubes were exposed to an additional transverse straining before cooling by injection of air (the sequential biaxial strain) as described by Løvdal et al ${ }^{17}$.

\section{Specimen preparation}

Specimens for mechanical testing were cut from the tubes both circumferentially and axially along the tube with a width $\mathrm{w}=5 \mathrm{~mm}$ and a length $\mathrm{L}=18 \mathrm{~mm}$. The cross-sectional area was determined as the average thickness times the width of the specimens.

\section{Mechanical testing}

Uniaxial tensile testing was performed according to ASTM D882 at a testing speed of $2.7 \mathrm{~mm} / \mathrm{min}$ (testing strain rate, $\dot{\epsilon}=0.15 / \mathrm{min}$ ) on an Instron 5564. Tensile testing was performed for specimens taken in both the axial and circumferential direction and tubes were pulled to fracture. Stress $(\sigma)$ is calculated as force over the initial cross sectional area $\left(\mathrm{A}_{0}\right)\left(\sigma=\frac{\mathrm{F}}{\mathrm{A}_{0}}\right)$ and strain $(\varepsilon)$ is the difference in length over the initial length $\left(\epsilon=\frac{\Delta \mathrm{L}}{\mathrm{L}_{0}}\right)$. From the stress-strain curves, elastic modulus (E) was determined in the interval of 20-40 MPa and yield stress $\left(\sigma_{y}\right)$ was determined as the local maximum. Statistically significant differences were defined at a confidence level of $5 \%$. 


\section{Differential scanning calorimetry (DSC)}

A differential scanning calorimeter (NETZSCH DSC 200 F3 Maia) was used to determine the thermal properties using NETZSCH Proteus Analysis software v 6.1. Samples (5-10 mg) were heated $\left(10{ }^{\circ} \mathrm{C} / \mathrm{min}\right)$ from $0{ }^{\circ} \mathrm{C}$ to $200{ }^{\circ} \mathrm{C}$ and a nitrogen atmosphere was obtained by flow of 50 $\mathrm{ml} / \mathrm{min}$. The $\mathrm{T}_{\mathrm{g}}$ was found as the midline between onset and offset of the transition. The degree of crystallinity $\left(\mathrm{X}_{\mathrm{c}}\right)$ was calculated from the measured enthalpy induced by melting $\left(\Delta \mathrm{H}_{\mathrm{m}}\right)$ minus the measured heat fusion induced by cold crystallization $\left(\Delta \mathrm{H}_{\mathrm{c}}\right)$ relative to the enthalpy of fusion $\left(\Delta \mathrm{H}^{\mathrm{o}}\right.$ $=93 \mathrm{~J} / \mathrm{g})^{19}$ of a $100 \%$ crystalline PLLA sample (Eq. 1). The reproducibility of identical samples is $0.06 \%$ in crystallinity and the variation between positions of samples in the heating chamber is $2 \%{ }^{17}$

$$
\mathrm{X}_{\mathrm{c}}(\%)=\frac{\left(\Delta \mathrm{H}_{\mathrm{m}}-\Delta \mathrm{H}_{\mathrm{c}}\right)}{\Delta \mathrm{H}^{\circ}} \cdot 100 \%(\text { Eq. 1) }
$$

\section{Wide angle X-ray scattering (WAXS)}

WAXS was used to determine the crystalline texture using a custom made 2D diffraction setup equipped with a rotating anode $\mathrm{Cu} \mathrm{K} \alpha \mathrm{X}$-ray source, monochromatized and focused by $1 \mathrm{D}$ multilayer optics $(\lambda=1.5418 \AA$ ). It was operated at $50 \mathrm{kV}$ and $200 \mathrm{~mA}$ with a $123 \mathrm{~mm}$ distance between detector and sample for exposures of $30 \mathrm{~min}$. The sample was cut in half and placed with the axial direction vertical and perpendicular to the beam.

The crystalline orientation of the lamellae in the straining direction was quantified using Herman's orientation function (Eq.2) and a second-order orientation factor (Eq. 3) ${ }^{20}$. A Herman's orientation factor $\left(\mathrm{F}_{2}\right)$ of 1 corresponds to complete orientation. The scattering intensity is integrated as a function of angle $2 \theta$ and the azimuthal angle $\phi$, where $\phi=0^{\circ}$ is defined as the position of the circumferential direction and the normal direction to the $(200 / 110)$ plane in the interval of scattering vectors $\mathrm{q}=1.13-1.24 \AA^{-1}$ between $0-360^{\circ}$.

$$
\mathrm{f}_{\mathrm{H}}=\frac{3\left\langle\cos ^{2} \phi\right\rangle-1}{2}
$$

where $\left\langle\cos ^{2} \phi\right\rangle$ is 


$$
\begin{gathered}
\left\langle\cos ^{2} \phi\right\rangle=\frac{\int_{0}^{\pi} I(\phi) \cos ^{2} \phi \sin \phi d \phi}{\int_{0}^{\pi} I(\phi) \sin \phi d \phi} \\
\mathbf{F}_{2}=-\mathbf{2} \cdot \mathbf{f}_{\mathbf{H}} \text { (Eq. 3) }
\end{gathered}
$$

The mean crystal size $\left(\mathrm{D}_{(\mathrm{hkl})}\right)$ (Eq. 4) was found in both circumferential direction (scattering vector $\mathrm{q}=2.2-2.25 \AA^{-1}$ ) and axial direction (scattering vector $\mathrm{q}=1.13-1.24 \AA^{-1}$ ) corresponding to the (018) and (110/200) planes, respectively, using Scherrer's equation with the shape factor $K=0.9^{11}$, the wavelength $\lambda=1.5418 \AA$ and $\beta 1 / 2$, which is the width at half the maximum of the peak height at the particular Bragg diffraction angle, $\theta$.

$$
\mathrm{D}_{(\mathrm{hkl})}=\frac{\mathrm{K} \cdot \lambda}{\beta_{1 / 2} \cos \theta} \text { (Eq. 4) }
$$

\section{RESULTS AND DISCUSSION}

\section{Tensile testing}

As expected, the circumferential tensile behavior (Figure 1) differs from the axial (Figure 2) ${ }^{17}$ When straining the circumferential test specimens above their yield point, a higher stress is required to further plastically deform the polymer (Figure 1), also known as strain-hardening. A $\dot{\epsilon}_{\mathrm{p}}=2.1 \mathrm{~s}^{-1}$ at $\mathrm{T}_{\mathrm{p}}=93^{\circ} \mathrm{C}$ gives the similar strain-hardening effect in the axial direction. It shows that strain-hardening phenomenon is present in both the circumferential and axial direction, if the $\dot{\epsilon}_{\mathrm{p}}$ and $\mathrm{T}_{\mathrm{p}}$ is high.

The axial stress-strain curve is higher for $\dot{\epsilon}_{\mathrm{p}}=2.1 \mathrm{~s}^{-1}$ at $\mathrm{T}_{\mathrm{p}}=73^{\circ} \mathrm{C}$ (Figure 2a) than for the lower $\dot{\epsilon}_{\mathrm{p}}$, which shows that the higher $\dot{\epsilon}_{\mathrm{p}}$ the more orientation can be achieved at this temperature. The trend is also seen at $\mathrm{T}_{\mathrm{p}}=93{ }^{\circ} \mathrm{C}$, but at $\mathrm{T}_{\mathrm{p}}=85{ }^{\circ} \mathrm{C}$ a low $\dot{\epsilon}_{\mathrm{p}}$ induces the highest strength. In the circumferential direction, the highest stiffness and strength is detected at an intermediate $\dot{\epsilon}_{\mathrm{p}}=0.2$ $\mathrm{s}^{-1}$. 

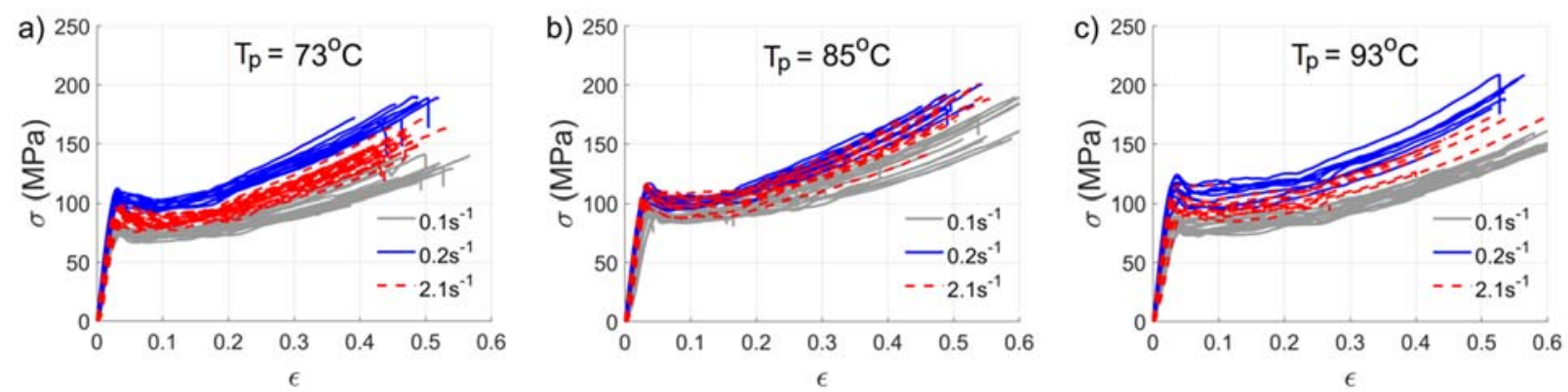

FIGURE 1 Nominal stress-strain curves for sequential, biaxially strained tubes in the circumferential direction processed at 3 different strain rates, $\dot{\epsilon}_{p} 0.1,0.2$ and $2.1 \mathrm{~s}^{-1}$ ) and temperatures, $\mathrm{T}_{\mathrm{p}}\left(73,85\right.$ and $\left.93{ }^{\circ} \mathrm{C}\right)$. Each color represents one set of specimens, processed under identical conditions.
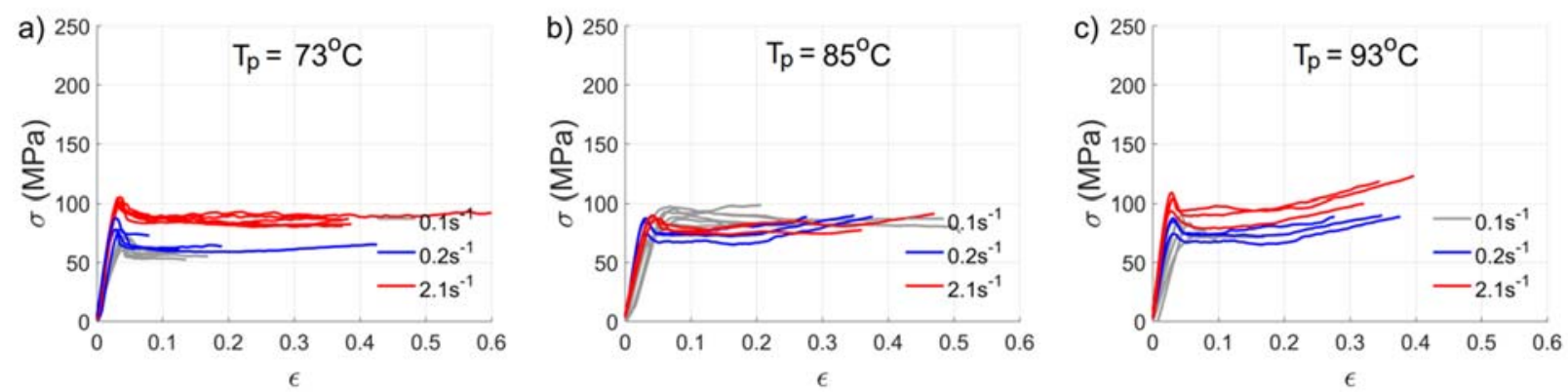

FIGURE 2 Nominal stress-strain curves for sequential, biaxially strained tubes in the axial direction processed at 3 different strain rates, $\dot{\epsilon}_{p}\left(0.1,0.2\right.$ and $\left.2.1 \mathrm{~s}^{-1}\right)$ and temperatures, $\mathrm{T}_{\mathrm{p}}(73,85$ and $93{ }^{\circ} \mathrm{C}$ ). Each color represents one set of specimens, processed under identical conditions.

Figure 1 also shows that the higher the $T_{p}$, the longer the elongation at break $\left(\epsilon_{b}\right)$. As the $\epsilon_{b}$ is often associated with cracks or imperfections within the polymer, the higher the $T_{p}$ the fewer imperfections within the polymer. The increased $\mathrm{T}_{\mathrm{p}}$ allows more mobility of the chains within the material during straining and results in fewer cracks and ultimately a longer $\epsilon_{\mathrm{b}}$. 
a)

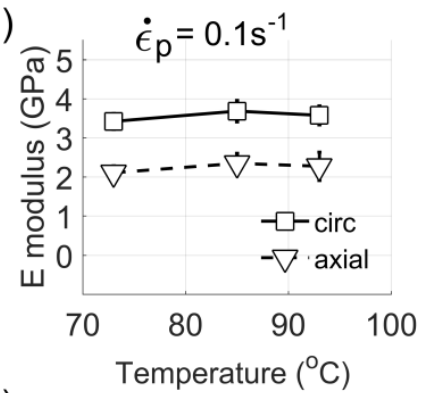

d)

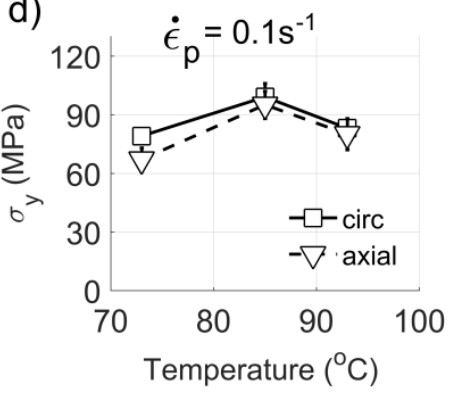

b)

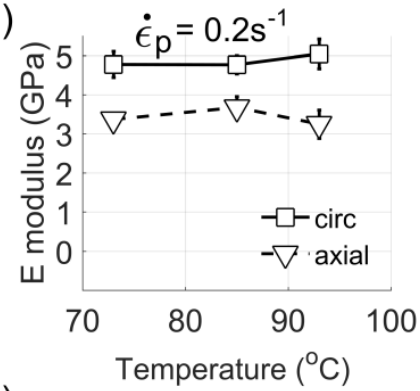

e)

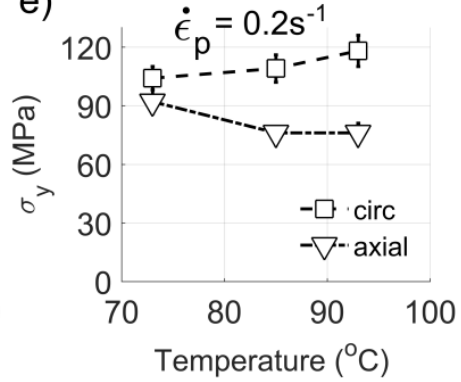

c)

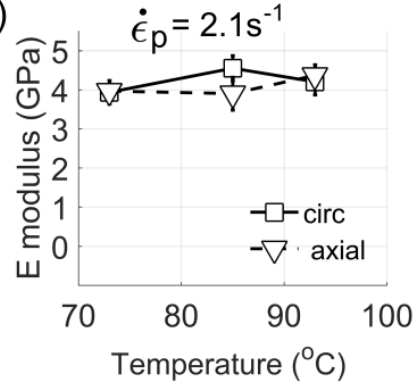

f)

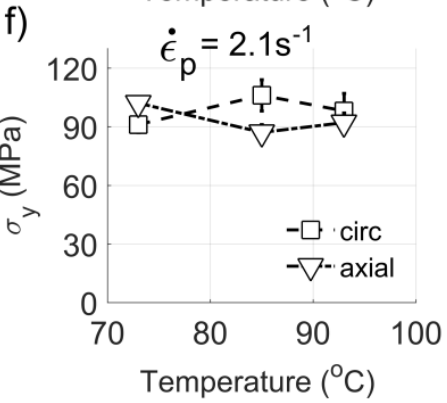

FIGURE 3 Elastic modulus $\left(\mathrm{E}_{20-40}\right)$ and yield stress $\left(\sigma_{\mathrm{y}}\right)$ of PLLA tubes obtained from tensile testing in both circumferential and axial directions as a function of processing temperature. Each value represents the average value along with the standard deviation.

Tubes strained at a low rate, $\dot{\epsilon}_{\mathrm{p}}=0.1 \mathrm{~s}^{-1}$ showed the smallest elastic modulus in the both the circumferential as well as the axial direction at all strain temperatures (Figure 3a). Such a low strain rate is thus not ideal for optimization of stiffness and strength. Increasing the $\dot{\epsilon}_{\mathrm{p}}$ results in a larger stiffness in both axial and circumferential directions which indicates that the molecular chains are more oriented. The results are less conclusive for the yield strength, where no apparent trend between processing strain and temperature is identified. Anisotropy is detected between the two directions at low $\dot{\epsilon}_{\mathrm{p}}=0.1 \mathrm{~s}^{-1}$ and $0.2 \mathrm{~s}^{-1}$. As previously shown, the axial strain of $100 \%$ at a $\dot{\epsilon}_{\mathrm{p}}=2.1 \mathrm{~s}^{-1}$, induces a large degree of orientation and $34 \%$ crystallinity $^{17}$. Exposing such strained tube to a large extent of transverse strain in this study induces the material with isotropy regardless of $T_{p}$ and the same stiffness and strength within the material as seen in Figure $3 \mathrm{f}$. The strain in the radial direction is four times higher and enough to create orientation in the circumferential direction. The initial orientation obtained in the axial direction is therefore not completely obliterated during the transverse strain as predicted by Ou et $\mathrm{al}^{21}$. An isotropic material in terms of elastic modulus and yield strength is only seen at a high strain rate $\left(\dot{\epsilon}_{\mathrm{p}}=2.1 \mathrm{~s}^{-1}\right)$. 
The supplier (NatureWorks) has done sheet extrusion at $190{ }^{\circ} \mathrm{C}$ of the same material, which leads to an elastic modulus of $3.5 \mathrm{GPa}, \varepsilon$ b of $6 \%$ and a yield strength of $60 \mathrm{MPa}$. The properties of the sheet are similar to what was obtained in the circumferential direction for a tube sequential biaxially strained at $\mathrm{T}_{\mathrm{p}}=73{ }^{\circ} \mathrm{C}$ but at a low $\dot{\epsilon}_{\mathrm{p}}$ (Figure $3 \mathrm{c}$ and $\mathrm{f}$ ). The highest elastic modulus and yield strength for biaxially strained tubes in this study is found at $\mathrm{T}=93{ }^{\circ} \mathrm{C}$ for $\dot{\epsilon}_{\mathrm{p}}=0.2 \mathrm{~s}^{-1}$ (Figure $3 b)$ in the circumferential direction $(5 \mathrm{GPa})$. The same relation does not hold for the axial direction, where the greatest modulus is seen at $\mathrm{T}_{\mathrm{p}}=93{ }^{\circ} \mathrm{C}$ for $\dot{\epsilon}_{\mathrm{p}}=2.1 \mathrm{~s}^{-1}$. For $\dot{\epsilon}_{\mathrm{p}}=0.1 \mathrm{~s}^{-1}$ or $\dot{\epsilon}_{\mathrm{p}}=0.2 \mathrm{~s}^{-1}$ both axial and circumferential moduli are unaffected by temperature, showing the same degree of anisotropy (Figure $3 \mathrm{a}$ and $\mathrm{b}$ ) as a function of $\mathrm{T}_{\mathrm{p}}$.

\section{Thermal analysis}

The mechanical behavior of a polymer is related to the morphology of the material ${ }^{9}$. The crystallinity and $\mathrm{T}_{\mathrm{g}}$ obtained at each $\mathrm{T}_{\mathrm{p}}$ and $\dot{\epsilon}_{\mathrm{p}}$ for axially or sequential, biaxially strained tubes are summarized in Table 1 and 2. As stated previously, the induced crystallinity depends on the straining temperature, the rate and the extent of strain. It is known that an axial strain of less than $100 \%$ does not induce any crystallinity ${ }^{22}$ which is also true for these particular PLLA tubes. However from this study it was seen that in order to induce crystallinity, the $\dot{\epsilon}_{\mathrm{p}}$ must be higher than $\dot{\epsilon}_{\mathrm{p}}=0.2 \mathrm{~s}^{-1}$ and the temperature must be $\mathrm{T}_{\mathrm{p}}=73{ }^{\circ} \mathrm{C}$ or lower (Figure $4 \mathrm{a}$ ). The same phenomenon is seen for polyethylene terephthalate when reducing the $\dot{\epsilon}_{\mathrm{p}}$, where a slower crystallization rate is detected, which causes a late crystallization during the first axial strain ${ }^{23}$. The slow $\dot{\epsilon}_{\mathrm{p}}$ does not allow the chains to be strained fast enough to trigger crystallization. Therefore a $\dot{\epsilon}_{\mathrm{p}}=0.1 \mathrm{~s}^{-1}$ or $\dot{\epsilon}_{\mathrm{p}}=0.2 \mathrm{~s}^{-1}$ at any of the three given temperatures will either provide the molecular chains enough time to relax after axial strain or the $\dot{\epsilon}_{\mathrm{p}}$ may be too slow for the chains to become oriented before the sequential biaxial strain is applied.

TABLE 1 Degree of crystallinity $\left(\mathrm{X}_{\mathrm{c}}\right)$ for tubes either sequential biaxially, strained or axially strained at temperature $T_{p}$ and different processing strain rates $\dot{\epsilon}_{\mathrm{p}}$

\begin{tabular}{cllll}
\hline Biaxial strain & & & & \\
\hline & & $\mathrm{X}_{\mathbf{c}}(\%)$ & $\mathrm{X}_{\mathbf{c}}(\%)$ & $\mathrm{X}_{\mathbf{c}}(\%)$ \\
\hline$\dot{\epsilon}_{\mathrm{p}}$ & & $2.1 \mathrm{~s}^{-1}$ & $0.2 \mathrm{~s}^{-1}$ & $0.1 \mathrm{~s}^{-1}$ \\
\hline & $\mathrm{T}_{\mathrm{P}}\left({ }^{\circ} \mathrm{C}\right)$ & & & \\
\hline
\end{tabular}




\begin{tabular}{|c|c|c|c|c|}
\hline & 73 & 32 & 31 & 31 \\
\hline & 85 & 31 & 34 & 30 \\
\hline & 93 & 31 & 29 & 30 \\
\hline \multicolumn{5}{|c|}{ Axial strain } \\
\hline \multirow{4}{*}{$\dot{\epsilon}_{\mathrm{p}}$} & & $2.1 \mathrm{~s}^{-1}$ & $0.2 \mathrm{~s}^{-1}$ & $0.1 \mathrm{~s}^{-1}$ \\
\hline & 73 & 33 & 1 & - \\
\hline & 85 & 2 & - & - \\
\hline & 93 & 0 & 1 & 0 \\
\hline
\end{tabular}

TABLE $2 \mathrm{~T}_{\mathrm{g}}$ for tubes either sequential, biaxially strained or axially strained at temperature $\mathrm{T}_{\mathrm{p}}$ and different processing strain rates $\dot{\epsilon}_{\mathrm{p}}$

\begin{tabular}{cllll}
\hline Biaxial strain & & & & \\
\hline & & $\mathbf{T}_{\mathbf{g}}\left({ }^{\circ} \mathbf{C}\right)$ & $\mathbf{T}_{\mathbf{g}}\left({ }^{\circ} \mathbf{C}\right)$ & $\mathbf{T}_{\mathbf{g}}\left({ }^{\circ} \mathbf{C}\right)$ \\
\hline$\dot{\epsilon}_{\mathrm{p}}$ & & $\mathbf{2 . 1 ~ s}^{\mathbf{1}}$ & $\mathbf{0 . 2 ~ s}^{-\mathbf{1}}$ & $\mathbf{0 . 1 ~}^{\mathbf{1}}$ \\
\hline & $\mathbf{T}_{\mathbf{p}}\left({ }^{\circ} \mathbf{C}\right)$ & & & \\
\hline 73 & 63 & 64 & 64 \\
\hline & 85 & 63 & 64 & 64 \\
\hline Axial strain & 93 & 63 & 64 & 63 \\
\hline$\dot{\epsilon}_{\mathrm{p}}$ & & & & \\
\hline & 73 & 62 & 61 & 62 \\
\hline & 85 & 60 & 61 & 62 \\
\hline & 93 & 59 & 60 & 59 \\
\hline
\end{tabular}
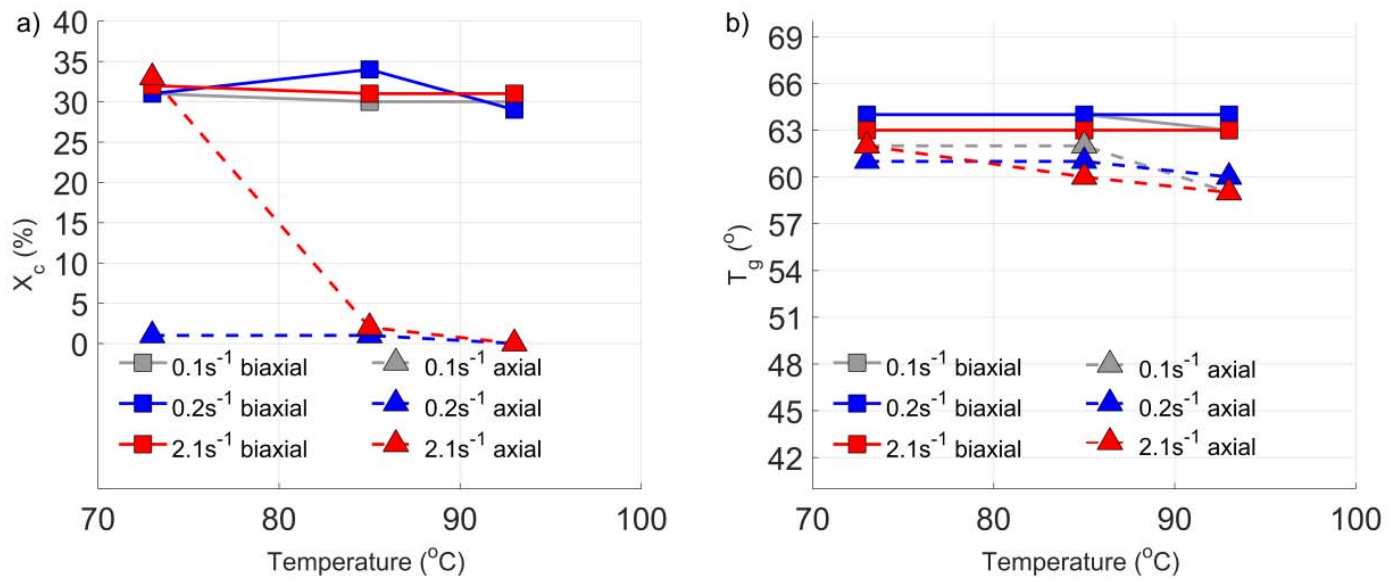

FIGURE 4 The degree of crystallinity $\left(\mathrm{X}_{\mathrm{c}}\right)$ and $\mathrm{T}_{\mathrm{g}}$ from DSC for axial and sequential biaxially strained tubes as a function of strain temperature and rate. Number of samples $n=1$ 
Overall little difference in crystallinity overall was detected for biaxially strained tubes regardless of $\dot{\epsilon}_{\mathrm{p}}$ or $\mathrm{T}_{\mathrm{p}}$. The final crystallinity of the biaxially strained tube is unaffected by the initial crystallinity obtained during the axial strain. It is natural to think that a low degree of crystallinity as seen for $\mathrm{T}_{\mathrm{p}}>73^{\circ} \mathrm{C}$ and $\dot{\epsilon}_{\mathrm{p}}<2.1 \mathrm{~s}^{-1}$ obtained during axial straining would induce less resistance to a transverse strain, thus a higher degree of chain orientation and crystallinity could therefore be obtained in the circumferential direction, but this is not the case. An axial strain at $\mathrm{T}_{\mathrm{p}}=73{ }^{\circ} \mathrm{C}$ and $\dot{\epsilon}_{\mathrm{p}}=2.1 \mathrm{~s}^{-1}$ induces $34 \%$ crystallinity in the polymer, yet the transverse strain applied to such axially strained tubes does not increase the crystallinity further.

A decreasing trend in $T_{g}$ is seen for the axially strained tubes as a function of $T_{p}$ (Figure $4 b$ ), which is not detected for the biaxially strained tubes. The $\mathrm{T}_{\mathrm{g}}$ for biaxially strained tubes is in general higher (Figure 4b), which means that the sequential biaxial strain results in tubes with more oriented chains, and more energy is needed to mobilize the chains further.

Previously $\mathrm{Wu}$ et $\mathrm{al}^{24}$ showed that the higher the $\dot{\epsilon}_{\mathrm{p}}$, the larger the $\mathrm{T}_{\mathrm{g}}$, at least for higher strain temperatures $\left(\mathrm{T}_{\mathrm{p}}=100^{\circ} \mathrm{C}\right)$. They also showed a slight decrease in crystallinity with increased $\dot{\epsilon}_{\mathrm{p}}$. This is true for most sequential biaxially strained tubes in this study. In terms of mechanical behavior, $\mathrm{Wu}$ et $\mathrm{al}^{24}$ also showed no change in stress-strain curves at $\mathrm{T}_{\mathrm{p}}=90^{\circ} \mathrm{C}$, despite a change in $\dot{\epsilon}_{\mathrm{p}}$, which is not true for sequential biaxially strained tubes in this study. In this study increasing the $\mathrm{T}_{\mathrm{p}}$ at a higher strain rate, reduces the elongation at break $\left(\epsilon_{\mathrm{b}}\right)$. This would normally be attributed to less mobility in the material if stretched at low temperatures or somewhat more rigid due to a higher degree of crystallinity. This is not the case for sequential biaxially strained tubes as the crystallinity for a $\dot{\epsilon}_{\mathrm{p}}=2.1 \mathrm{~s}^{-1}$ remains constant and the shorter $\epsilon_{\mathrm{b}}$ is most likely related to a higher degree of cavitations or microvoids formed during the transverse strain.

\section{Crystal orientation and crystal sizes}

It has previously been shown that a sequential biaxial strain induces a low crystal orientation factor $\left(\mathrm{F}_{2}\right)$ of approximately 0.3 at $\mathrm{T}_{\mathrm{p}}=73{ }^{\circ} \mathrm{C}$ and a $\dot{\epsilon}_{\mathrm{p}}=2.1 \mathrm{~s}^{-1} 18$. In this study, we observed that the crystal orientation is further diminished, as a function of strain temperature from $F_{2}=0.3$ to $F_{2}=$ 0.1. Furthermore reducing the $\dot{\epsilon}_{\mathrm{p}}=2.1 \mathrm{~s}^{-1}$ to $\dot{\epsilon}_{\mathrm{p}}=0.1 \mathrm{~s}^{-1}$ reduces the orientation factor as well $\left(\mathrm{F}_{2}\right.$ 
$=0.03)$ (see Figure 5). When $\dot{\epsilon}_{\mathrm{p}}$ is large compared to the chain relaxation rate the crystallization is delayed. When $\dot{\epsilon}_{\mathrm{p}}$ is small compared to the chain relaxation rate the chain relaxes and no crystal orientation occurs, which was also detected at a $\dot{\epsilon}_{\mathrm{p}}=0.1 \mathrm{~s}^{-1}$ at $\mathrm{T}_{\mathrm{p}}=93{ }^{\circ} \mathrm{C}$ (Figure 5c). The isotropic rings corresponding to equilibrium crystallization on the WAXS images (Figure 5a and b) are more predominant relative to textured diffraction peaks at higher strain temperatures. The phenomenon is normally seen for isothermal equilibrium crystallization ${ }^{8}$, as opposed to the more oriented plane reflection in (200/110) after straining (see Figure 5c). Zhang et $\mathrm{al}^{10}$ showed that the higher the strain temperature, the more orientation is seen for the $(200 / 110)$ plane. This is not detected when increasing strain temperature from $\mathrm{T}_{\mathrm{p}}=73{ }^{\circ} \mathrm{C}$ to $\mathrm{T}_{\mathrm{p}}=93{ }^{\circ} \mathrm{C}$. When increasing the $\mathrm{T}_{\mathrm{p}}$ for a biaxial strain, the crystal size in the axial direction decreases from $129 \AA$ to $116 \AA$ and the crystal size circumferentially decreased from $60 \AA$ to $21 \AA$. Despite the temperature increase the crystallinity is approximately the same after straining, and if no crystals are formed during the axial strain at higher temperatures, it allows smaller crystals to be formed as the transverse strain is applied. An increase from $\dot{\epsilon}_{\mathrm{p}}=0.1 \mathrm{~s}^{-1}$ to $\dot{\epsilon}_{\mathrm{p}}=2.1 \mathrm{~s}^{-1}$ results in an axial crystal size increase from $118 \AA$ to $129 \AA$ and a circumferential size decrease from $65 \AA$ to $60 \AA$. It is not known if the crystal size can be attributed to the difference in mechanical properties for each $\dot{\epsilon}_{\mathrm{p}}$.

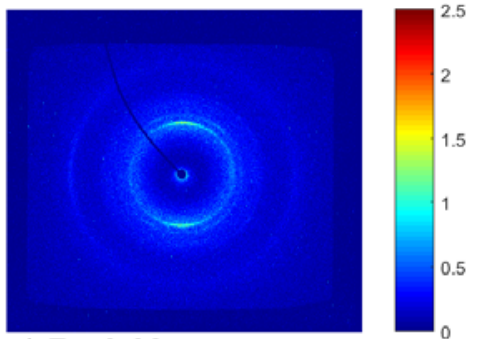

a) $F_{2}=0.03$

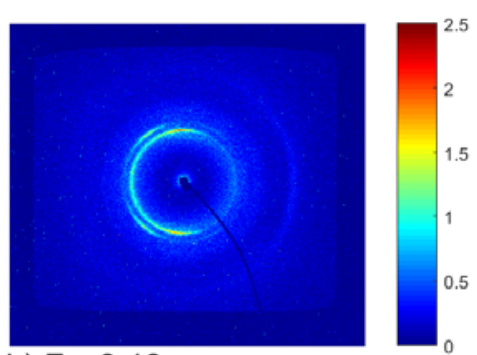

b) $F_{2}=0.10$

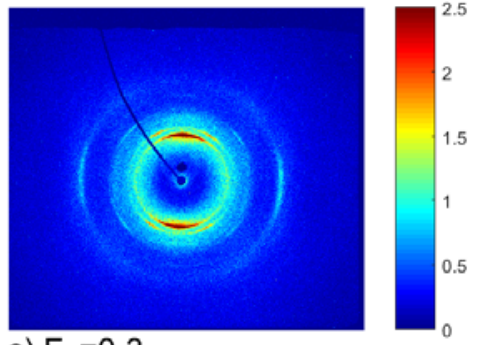

c) $F_{2}=0.3$

FIGURE 5 WAXS images of sequential, biaxially strained tubes after a $\dot{\boldsymbol{\epsilon}}_{\mathbf{p}}=0.1 \mathrm{~s}^{-1}$ (a) and $2.1 \mathrm{~s}^{-1}$ (b) at $93{ }^{\circ} \mathrm{C}$ and $2.1 \mathrm{~s}^{-1}$ at $73{ }^{\circ} \mathrm{C}$ (c). 


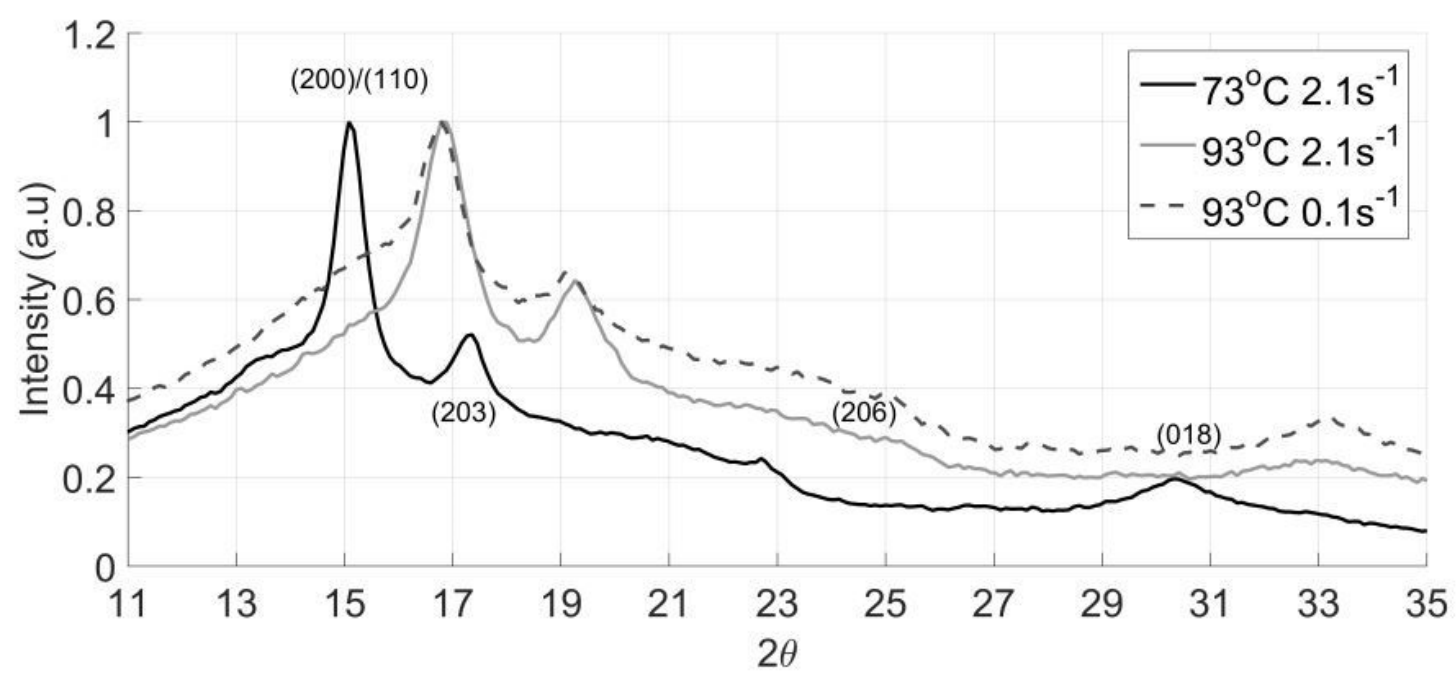

FIGURE 6 WAXS intensity plot as a function of scattering angle (2 $\theta)$ and the corresponding crystal planes for sequential biaxially strained tubes at strain temperatures $73^{\circ} \mathrm{C}$ or $93{ }^{\circ} \mathrm{C}$ and $\dot{\epsilon}_{\mathrm{p}}=$ $0.1 \mathrm{~s}^{-1}$ or $\dot{\epsilon}_{\mathrm{p}}=2.1 \mathrm{~s}^{-1}$. Intensity for $\dot{\epsilon}_{\mathrm{p}}=0.1 \mathrm{~s}^{-1}$ or $\dot{\epsilon}_{\mathrm{p}}=2.1 \mathrm{~s}^{-1}$ strain at $\mathrm{T}_{\mathrm{p}}=93{ }^{\circ} \mathrm{C}$ is scaled by a factor of 7 and 8 , respectively.

The WAXS intensity plot for $\mathrm{T}_{\mathrm{p}}=73^{\circ} \mathrm{C}$ at $\dot{\epsilon}_{\mathrm{p}}=2.1 \mathrm{~s}^{-1}$ in Figure 6 shows a formation of $\alpha$ ' crystals with peaks at $2 \theta=15.1,17.3,22.8$, and 30.4 corresponding to the lattice planes (200/110), (203), (206) and (018), respectively. When the temperature is increased to $\mathrm{T}_{\mathrm{p}}=93{ }^{\circ} \mathrm{C}$, the peaks are shifted right, indicating a decrease in interplanar spacing which means that the crystals are packed more closely and the material would be stiffer ${ }^{25}$. However, these findings cannot not explain the mechanical behavior of the tubes and it is inferred that the crystal packaging does not affect the mechanical performance of the tubes.

It is thus seen that the enhancement of mechanical stiffness and strength for PLLA must be very sensitive to both the processing strain rate and the processing temperature. Both circumferential and axial stiffness and strength benefit from a high axial processing strain rate, as the molecular chains does not have enough time to relax during the axial strain. Additionally the process allows the material to become isotropic in terms of stiffness and yield strength as a result thereof.

\section{CONCLUSION}


Straining PLLA either through an axial or biaxial strain has proven to alter the crystal orientation and chain orientation, and possibly cause formation of fibrils and the appearance of cavitations, which improves the strength and stiffness significantly. Both increasing strain rate and temperature improve the strength and stiffness and orient the crystals. In this study, sequential biaxially strained PLLA tubes were processed at different temperatures and strain rates, and it was seen that PLLA must be processed above $\mathrm{T}_{\mathrm{g}}$ but below $85{ }^{\circ} \mathrm{C}$ to ensure the formation of crystals. The initial axial strain-induced crystallinity is suppressed at higher processing strain temperatures $\left(\mathrm{T}_{\mathrm{p}}=85^{\circ} \mathrm{C}\right.$ and $\mathrm{T}_{\mathrm{p}}=93{ }^{\circ} \mathrm{C}$ ). It is favorable to increase strain temperature to at least $\mathrm{T}_{\mathrm{p}}=85^{\circ} \mathrm{C}$ and choose a lower strain rate by increasing chain relaxation, suppressing chain orientation process as well as straininduced crystallinity. At lower strain rates chain relaxation occurs and orientation of the amorphous chains during the axial strain is not realized. Lower strain rates would therefore induce a larger elastic modulus and yield strength circumferentially than axially, and the material appears anisotropic. Although it was possible to obtain an isotropic material at a processing strain rate of $2.1 \mathrm{~s}^{-1}$, yet it did not yield the largest modulus or strength. 


\section{References}

1. Lasprilla, A.J.R., Martìnez, G.A.R, Lunelli, B.H., Jardini, A.L. and Filho, R.M. Biotechnol. Adv. 2012, 30, 321-328.

2. Nair, L.S. and Laurencin, C.T. Prog. Polym. Sci. 2007, 32, 762-798.

3. Jagur-Grodzinski, J. Polym. Adv. Technol. 2006, 17, 395-418.

4 Nampoothiri, K.M., Nair, N.R. and John, R.P. Bioresour. Technol. 2010, 101, 8493-8501.

5. Tanaka, M. and Young, R. J. Biomacromolecules, 2006, 7, 2575-2582.

6. Arnoult, M., Dargent, E., Mano, J. F. Polymer, 2007, 48, 1012-1019.

7. Velazquez-Infante, J.C., Gámez-Péres, J., Franco-Urquiza, E. A., Santana, O. O., Carrasco, F. and Maspoch, M. L.J Appl Polym Sci, 2013, 127, 2661-2669.

8. Liu J, Zhang S, Zhang L, Liu L, Bai Y, Eur. Polym. J., 2014, 61: 83-92.

9. Stoclet, G., Séguéla, R., Vanmansart, C., Rochas, C. and Lefebvre, J.M. Polymer, 2012, 53 , 519-528.

10. Zhang, X., Schneider, K., Liu, G., Chen, J., Brüning, K., Wang, D. and Stamm, M. Polymer, 2012, 53, 648-656.

11. Zhang, X., Schneider, K., Liu, G., Chen, J., Brüning, K., Wang, D. and Stamm, M. Polymer, 2011, 52, 4141-4149.

12. Delpouve, N., Delbreilh, L., Stoclet, G., Saiter, A. and Dargent, E., Macromolecules, 2014, 47, $5186-5197$.

13. Lee, J. K., Lee, K. H., Jin, B. S., Eur. Polym. J., 2001, 37, 907-914.

14. Rangari D, Vasanthan N, Macromolecules, 2012 , 45, 7397-7403.

15. Mahendrasingam, A., Blundell, D.J., Parton, M., Wright, A.K., Rasburn, J., Narayanan, T. and Fuller, W. Polymer, 2005, 46, 6009-6015.

16. Chen, X., Kalish, J. and Hsu, S.L., J. Polym. Sci., Part B: Polym. Phys. 2011, 49, 1446-1454.

17. Løvdal, A.L.V., Andreasen, J. W., Mikkelsen, L. P., Agersted, K., Almdal, K., Polym Int, 2016, $65,133-141$.

18. Cifuentes, S. C., Frutos, E., Benavente, R., Gonzáles-Carrosco, J. L., Lorenzo, V., Eur. Polym. J., 2014, 59, 239-246.

19. Wunderlich, B.; Thermal Analysis, Academic Press: Boston, 1990, pp. 417-431. 
20. Sakurai, S., Aida, S., Okamoto, S., Ono, T., Imaizumi, K. and Nomura, S., Macromolecules, 2001, 34, 3672-3678.

21. Ou, X. and Cakmak M. Polym., 2008, 49, 5344-5352.

22. Stoclet, G., Séguéla, R., Lefebvre, J.M., Elkoun, S. and Vanmansart, C., Macromolecules, 2010, 43, 1488-1498.

23. Mahendrasingam, A., Blundell, D.J., Martin, C., Fuller, W., MacKerron, D.H., Harvie, J.L., Oldman, R.J. and Riekel, C. Polymer, 2000, 41, 7803-7814.

24. Wu, J., Yen, M., Wu, C., Li, C. and Kuo, M. C. J. Polym. Environ., 2013, 21, 303-311.

25. Saeidlou, A., Huneault, M.A., Li, H. and Park, C.B. Prog. Polym. Sci., 2012, 37, 1657-1677 . 


\section{Graphical abstract}

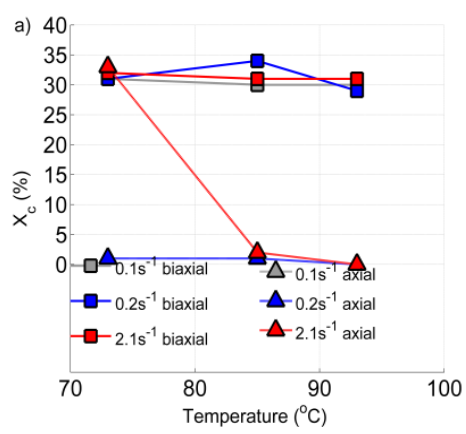

The degree of crystallinity $\left(\mathrm{X}_{\mathrm{c}}\right)$ for axial and sequential, biaxially strained tubes as a function of strain temperature and rate. Number of samples $n=1$ 